\title{
Clinical presentations and hemodynamic parameters in patients hospitalized due to acute heart failure stratified by the left-ventricular ejection fraction
}

\author{
Corresponding author: \\ Agata Galas \\ Military Institute of Medicine, Head \\ of Department of Cardiology and \\ Internal Diseases \\ Szaserów 128 St \\ 04-141 Warsaw, Poland \\ phone: 261-817-358 \\ e-mail: agalas@wim.mil.pl
}

Medical Research Journal 2018; Volume 3, Number 4, 195-203 10.5603/MRJ.a2018.0032 Copyright (C) 2018 Via Medica ISSN 2451-2591

\begin{abstract}
Background: Currently, one of the most common causes of hospitalization, especially in the elderly, is heart failure (HF) exacerbation. In nearly $95 \%$ of patients, this is caused by fluid overload. There have been studies comparing the rates of comorbidities and biochemical disturbances in HF patients; however, their hemodynamic parameters have not yet been assessed. Thus, the aim of this study was to compare the clinical presentations and hemodynamic parameters assessed via impedance cardiography (ICG) in patients hospitalized due to acute HF, stratified by the left-ventricular ejection fraction (LVEF).

Methods: This study enrolled 102 patients, aged $>18$ years, hospitalized due to decompensated HF. Ninety-seven patients (74 men, 23 women) underwent echocardiographic examination. Biochemical and hemodynamic parameters were assessed on the day of admission and, subsequently, every other day during hospitalization. Based on echocardiographic findings and the ESC guidelines the study group was divided into the following subgroups: HFrEF (EF $<40 \%$ ), HFpEF (EF $>50 \%$ ), and HFmrEF (EF 40-49\%).

Results: The HFrEF group, which constituted $60.8 \%$ of patients $(n=58)$, was predominantly male $(P=$ 0.0005); and most had elevated $N$-terminal pro-brain natriuretic peptide levels $(P=0.0008)$. The HFpEF and HFmrEF subgroups, jointly $(n=38)$, were characterized by higher systolic blood pressure $(P=0.0001)$, and lower hemoglobin levels $(P=0.003)$. The hemodynamic assessment showed that HFrEF patients had higher total fluid content $(P=0.005)$ and lower systolic time ratio $(P=0.0002)$.

Conclusions: Despite similar clinical presentation, patients with HF exhibited different values of hemodynamic and biochemical parameters depending on their LVEF; this indicates non-homogeneity of pathomechanisms and causes of HF decompensation.
\end{abstract}

Key words: heart failure, acute heart failure, hemodynamic parameters, impedance cardiography, left-ventricular ejection fraction

Med Res J 2018; 3 (4): 195-203

\section{Introduction}

Diagnostics and treatment of acute heart failure (AHF) are one of the key problems in intensive cardiac care [1]. The prognosis remains poor, with in-hospital mortality of $4.1-13.9 \%$ [2-6]. The current European Society of Cardiology (ESC) guidelines emphasize the need for urgent AHF management [2, 7]. In order to be effective, management should be based on detailed clinical assessment, aiming to identify the key mechanism of cardiovascular decompensation [8]. Whereas most patients with heart failure (HF) and left-ventricular ejection fraction (LVEF) $<40 \%$ (i.e. HF with reduced ejection fraction, HFrEF) exhibit evidence of fluid accumulation and fluid redistribution to the lungs, which leads to pulmonary congestion, those with HF with midrange (mildly reduced) ejection fraction (HFmrEF) and HF with preserved ejection fraction (HFpEF) typically 
show more diverse pathomechanisms [9-13]. The latter two subgroups (HFmrEF and HFpEF) constitute an increasing proportion of patients with AHF $[14,15,16]$. These patients are typically elderly, often with concomitant diabetes mellitus, hypertension, atrial fibrillation, and/or obesity $[17,18]$. Their treatment may, therefore, present more challenges, as recommendations for their management are based mainly on expert opinions.

Thus, it is useful to search for diagnostic methods that would provide additional data compared to that obtained from routine assessments, while at the same time being simple enough to be used in intensive-care settings. These conditions seem to be met by impedance cardiography (ICG), a simple, non-invasive method of assessing the hemodynamic parameters that reflect the cardiac function as a pump (including cardiac index $(\mathrm{Cl})$, stroke index (SI), systemic vascular resistance index (SVRI)) and thoracic fluid content (TFC) [19].

Therefore, the aim of this study was to compare clinical presentations between subgroups of patients hospitalized for AHF stratified by LVEF, with a particular emphasis on their hemodynamic profiles.

\section{Methods}

This prospective, observational study enrolled patients of both sexes, aged > 18 years, who were admitted to the Department of Cardiology and Internal Diseases due to decompensated HF (defined based on ESC guidelines) in the period between November 2014 and March 2017 and required intravenous diuretic treatment.

Exclusion criteria were: 1) unstable angina; 2) history of acute coronary syndrome (ACS) within the last 12 weeks and/or coronary artery bypass grafting (CABG) surgery within the last 12 weeks; 3) cardiac resynchronization therapy (CRT) introduced within the last year (or planned CRT implantation within the next 24 months); 4) non-cardiogenic shock; 5) valvular disease or other acquired heart defects requiring surgical intervention; 6) hypertrophic cardiomyopathy; 7) severe pulmonary hypertension or other severe lung condition (severe form of chronic obstructive pulmonary disease (COPD) or bronchial asthma); 8) poorly controlled hypertension; 9) anaemia (haemoglobin < $10.0 \mathrm{~g} / \mathrm{dL}$ ); 10) acute and/or decompensated non-cardiovascular disease; 11) end-stage CKD and/or ongoing hemodialysis therapy; 12) severe or chronic inflammatory disease, severe infection (including febrile conditions, radiologically-confirmed pneumonia, suspected septic shock); 13) neoplastic disease; 14) severe psychiatric disorder; 15) the lack of informed consent.

The study protocol was approved by the Military Institute of Medicine Institutional Review Board (approval No. 14/WIM/2012), and all study participants provided their written informed consent. This study was registered at ClinicalTrials.gov (NCT 02355769).

Clinical examinations were conducted with a particular emphasis on the history of symptoms, concomitant diseases, and current medication. The following were measured on physical examination: heart rate $(\mathrm{HR})$, office systolic blood pressure (SBP), office diastolic blood pressure (DBP), and basic body parameters.

Laboratory tests were conducted on fasting peripheral venous blood samples, collected in the morning (7:30-8:30 a.m.). The following hematological and biochemical parameters were measured: hematocrit, as well as hemoglobin, urea, creatinine, N-terminal pro-brain natriuretic peptide (NTproBNP), high-sensitivity troponin T (hsTnT) levels. The estimated glomerular filtration rate (eGFR) was estimated based on the Modification of Diet in Renal Disease (MDRD) study equation [20].

Echocardiographic examinations were conducted with Vivid S6 (GE-Healthcare, USA) and Vivid 7 (GE-Healthcare, USA) ultrasound systems and evaluated cardiac chamber dimensions, left ventricular wall thickness and contractility, ejection fraction with the biplane Simpson's method, as well as valvular structure and function. Echocardiography reports included any moderate-to-severe mitral, tricuspid, and/or aortic regurgitation; severe aortic stenosis; as well as the numerical values of the following parameters: left ventricular end-diastolic diameter (LVEDD), right ventricular end-diastolic diameter (RVEDD), interventricular septum (IVS), left atrial (LA) diameter, measured in the parasternal long-axis view.

Impedance cardiography (ICG). All ICG measurements were performed with the Niccomo ${ }^{\mathrm{TM}}$ device (Medis, Germany) within 24 hours of admission, after 10 minutes of rest in a sitting position. Data was recorded during a 10-minute assessment and exported to the dedicated software (Niccomo Software). The final analysis included mean values of hemodynamic parameters, such as: TFC [1/kOhm], calculated from basic impedance (Z0) as its reciprocal: TFC = 1000/Z0; $\mathrm{SI}$, calculated using the Sramek and Bernstein formula for stroke volume $(\mathrm{SV})=\mathrm{VEPT} \times d Z_{\max } \times \mathrm{LVET} / \mathrm{ZO}$ and indexed to body surface area to yield $\mathrm{SI}\left[\mathrm{mL} / \mathrm{m}^{2}\right] ; \mathrm{Cl}$ $\left[(\mathrm{mL} / \mathrm{min}) / \mathrm{m}^{2}\right]$, calculated as $\mathrm{SI} \times \mathrm{HR}$; acceleration index $\left(\mathrm{ACl}\left[1 / 100 * \mathrm{Ohm} / \mathrm{s}^{2}\right]\right)$, expressing the maximum acceleration of blood in the aorta from the moment the aortic valve opens; velocity index (VI [1/1000* Ohm/s] expressing the maximum velocity of blood in the aorta from the moment the aortic valve opens; Heather index $\left(\mathrm{HI}\left[\mathrm{Ohm}{ }^{*} \mathrm{~s}^{2}\right]\right)$, characterizing the maximum contraction force of the left ventricle, corresponding to cardiac inotropism; SVRI [(dyn $\left.\left.\times \mathrm{s}) / \mathrm{cm}^{5} / \mathrm{m}^{2}\right)\right]$, calculated as $80 \times(\mathrm{MBP}-\mathrm{CVP}) / \mathrm{Cl}$, where CVP is central venous pressure (with an assumed value of $6 \mathrm{~mm} \mathrm{Hg}$ ). 


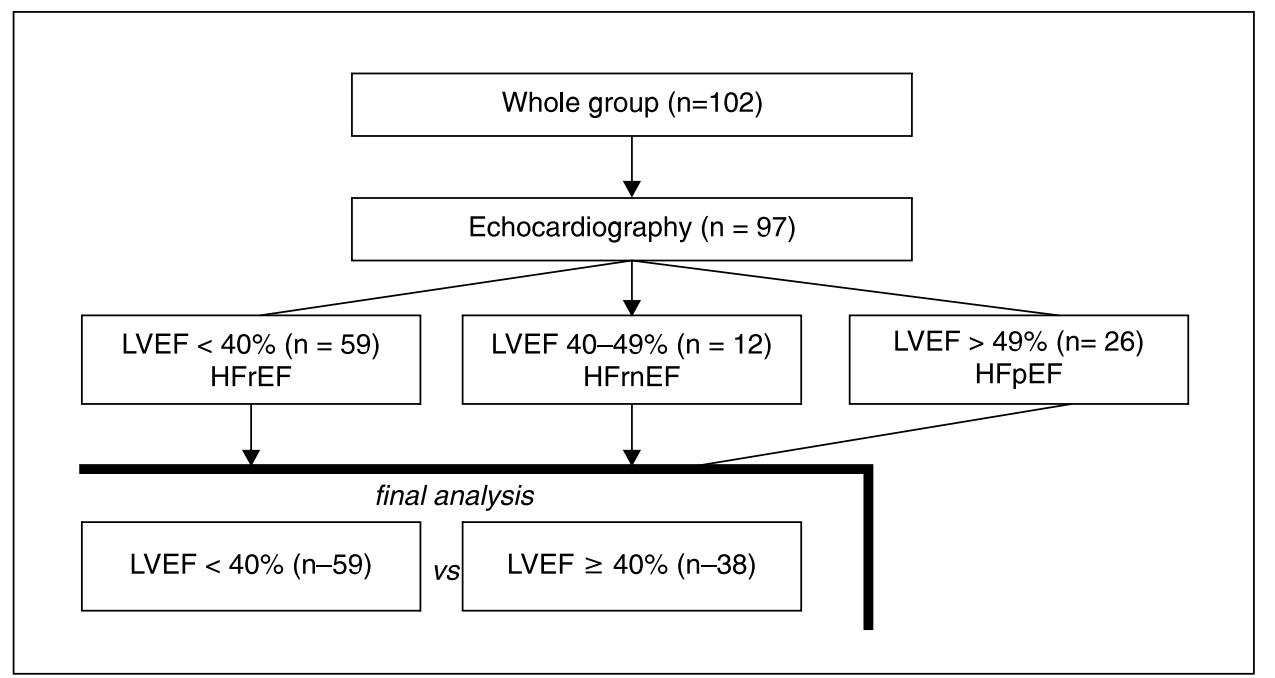

Figure 1. Analysis assumptions - compared subgroups (HFrEF — heart failure with reduced left ventricular ejection fraction; HRmrEF — heart failure with mid-range left ventricular ejection fraction; HFpEF — heart failure with preserved left ventricular ejection fraction, LVEF — left ventricular ejection fraction)

Statistical analysis. The statistical analysis of data was conducted with the use of MS Office Excel 2013 and Statistica 12.0 (StatSoft Inc.). Data distribution was presented on histograms and evaluated visually. The results for qualitative variables were expressed as numbers and percentages; while continuous (quantitative) variables were expressed as means \pm standard deviation (SD). For a comparative analysis, the study group was divided into two subgroups: patients with LVEF $<40 \%(n=59)$ and LVEF $\geq 40 \%(n=38)$ (Figure 1).

\section{Results}

\section{Clinical characteristics}

The subgroup with LVEF $<40 \%$ comprised predominantly men with ischemic HF etiology. These patients were younger than those in the LVEF $\geq 40 \%$ subgroup (Table 1). Nonetheless, the two groups showed no significant differences in terms of the New York Heart Association (NYHA) functional class, rates of dyspnea, or a history of edema, or pathological weight gain. Physical examination of patients with higher LVEF showed higher blood pressure values, higher rates of peripheral edema, and lower rates of peripheral hypoperfusion. The subgroups differed only slightly in terms of medication, with higher rates of angiotensin-converting enzyme (ACE) inhibitors in the LVEF $\geq 40 \%$ subgroup.

The echocardiographic examination showed the mean LVEF value in the study population of $37.3 \pm 14.1 \%$, LVEDD of $59.2 \pm 10.2 \mathrm{~mm}$, RVEDD of
$35.3 \pm 5.7 \mathrm{~mm}$, and LA dimeter of $47.3 \pm 0.60 \mathrm{~mm}$. In comparison, patients with LVEF $<40 \%$ had larger cardiac chamber dimensions, higher rates of moderate/severe mitral regurgitation, with lower rates of moderate/severe aortic stenosis (Table 2).

The mean NT-proBNP level in the LVEF $<40 \%$ subgroup was significantly higher than that in the subgroup with better LVEF (Table 3). There was a significant correlation between LVEF values and NT-proBNP levels $(R=-0.38 ; P<0.0001)$. At the same time, patients with LVEF $\geq 40 \%$ had significantly lower hemoglobin levels and hematocrit values, with comparable markers of renal function.

The two compared subgroups differed significantly in terms of hemodynamic profiles. Patients with LVEF < 40\% exhibited lower SBP values, lower values of cardiac function as a pump $(\mathrm{SI}, \mathrm{Cl}, \mathrm{HI}, \mathrm{ACl}, \mathrm{VI})$, higher TFC, and a less favourable ratio of pre-ejection period (PEP) to left ventricular ejection time (LVET) (Table 4, Fig. 2). These differences were confirmed when we assessed the correlation of these parameters with LVEF.

\section{Discussion}

our findings demonstrated that the clinical presentation of decompensated HFrEF differs from that of HFmrEF/HFpEF. Our observations regarding age differences, sex distribution, HF etiology, echocardiographic findings, and comorbidities are essentially consistent with those presented in earlier reports. Impedance cardiography proved to significantly differentiate patients from the two evaluated subgroups. Patients with higher 
Table 1. The comparison between patients with LVEF $<40 \%$ and LVEF $\geq 40 \%$ - patients characteristics

\begin{tabular}{|c|c|c|c|c|}
\hline & $\begin{array}{c}\text { LVEF }<40 \% \\
N=59\end{array}$ & $\begin{array}{c}\text { LVEF } \geq \mathbf{4 0} \% \\
\mathbf{N}=\mathbf{3 8}\end{array}$ & $\mathbf{P}$ & $\begin{array}{c}\text { Whole group } \\
\qquad \begin{array}{c}\mathrm{N}=97\end{array}\end{array}$ \\
\hline \multicolumn{5}{|c|}{ n (\%)/ mean \pm SD } \\
\hline Age, mean \pm SD & $68.1 \pm 13.2$ & $76.7 \pm 9.5$ & 0.0005 & $71.5 \pm 12.6$ \\
\hline Male, mean \pm SD & $50(84.8)$ & $24(63.2)$ & 0.015 & 74 (76.3) \\
\hline \multicolumn{5}{|l|}{ NYHA class } \\
\hline Mean class NYHA [-], mean \pm SD & $3.32 \pm 0.57$ & $3.32 \pm 0.52$ & 0.897 & $3.32 \pm 0.55$ \\
\hline class III, n (\%) & $37(62.7)$ & $25(65.8)$ & 0.773 & $62(63.9)$ \\
\hline class IV, n (\%) & $22(67.3)$ & $13(34.2)$ & 0.773 & $35(36.1)$ \\
\hline HF de novo, n (\%) & $16(27.1)$ & $10(26.3)$ & 0.931 & $26(26.8)$ \\
\hline Ischemic etiology, $\mathrm{n}(\%)$ & $41(69.5)$ & $21(55.3)$ & 0.003 & $62(63.9)$ \\
\hline \multicolumn{5}{|l|}{ CLINICAL EXAMINATION } \\
\hline Dyspnea at rest, n (\%) & $26(44.1)$ & $15(39.5)$ & 0.655 & $41(42.3)$ \\
\hline Dyspnea on effort, n (\%) & $58(98.3)$ & $38(100.0)$ & 0.420 & $96(99.0)$ \\
\hline Orthopnoe, n (\%) & $45(77.6)$ & $30(79.0)$ & 0.875 & $75(77.3)$ \\
\hline Edema, $\mathrm{n}(\%)$ & $44(74.6)$ & $31(81.6)$ & 0.421 & $75(77, .3)$ \\
\hline Pathological weight gain, $\mathrm{n}(\%)$ & $23(39.0)$ & $14(36.8)$ & 0.832 & $37(38.1)$ \\
\hline \multicolumn{5}{|l|}{ PHYSICAL EXAMINATION } \\
\hline $\mathrm{HR}[\mathrm{bpm}]$, mean $\pm \mathrm{SD}$ & $89.4 \pm 25.3$ & $82.3 \pm 20.1$ & 0.220 & $86.6 \pm 23.5$ \\
\hline $\mathrm{SBP}[\mathrm{mmHg}]$, mean $\pm \mathrm{SD}$ & $127.3 \pm 25.6$ & $147.2 \pm 27.0$ & 0.0001 & $135.1 \pm 27.2$ \\
\hline $\mathrm{DBP}[\mathrm{mmHg}]$, mean $\pm \mathrm{SD}$ & $80.2 \pm 12.8$ & $83.3 \pm 12.8$ & 0.282 & $81.4 \pm 13.5$ \\
\hline $\mathrm{BMI}\left[\mathrm{m}^{2} / \mathrm{kg}\right]$, mean (SD) & $28.9 \pm 5.8$ & $31.5 \pm 6.9$ & 0.094 & $29.9 \pm 6.3$ \\
\hline Hypertension (SBP > 140mmHg, DBP >90mmHg), $n(\%)$ & $6(10.2)$ & $19(50.0)$ & 0.00006 & $25(25.8)$ \\
\hline Hypotension (SBP < 90mmHg), n (\%) & $3(5.1)$ & $2(5.3)$ & ns & $5(5.2)$ \\
\hline Tachypnoe, n (\%) & $14(23.7)$ & $6(15.8)$ & 0.345 & $20(20.6)$ \\
\hline Rales, n (\%) & $58(98.3)$ & $38(100.0)$ & 0.783 & $96(99.0)$ \\
\hline Edema, n (\%) & $40(67.8)$ & $34(89.5)$ & 0.014 & $74(76.3)$ \\
\hline Peripheral hipoperfusion, $\mathrm{n}(\%)$ & $9(15.3)$ & $1(2.6)$ & 0.046 & $10(10.3)$ \\
\hline \multicolumn{5}{|l|}{ CONCOMITANT DISEASE } \\
\hline Prior MI, n (\%) & $32(54.2)$ & $10(26.3)$ & 0.007 & $42(43.3)$ \\
\hline Hypertension, n (\%) & $34(57.6)$ & $30(79.0)$ & 0.031 & $64(66.0)$ \\
\hline Atrial fibrillation, n (\%) & $29(49.2)$ & $22(57.9)$ & 0.400 & $51(52.6)$ \\
\hline Moderate-to-severe valvular disease, n (\%) & $18(30.5)$ & $15(39.5)$ & 0.477 & $33(34.0)$ \\
\hline Procedure: ICD, n (\%) & $10(17.0)$ & $0(0.0)$ & 0.040 & $10(10.3)$ \\
\hline Procedure: CRT, n (\%) & $5(8.5)$ & $1(2.6)$ & 0.040 & $6(6.2)$ \\
\hline Diabetes mellitus, n (\%) & $29(49.2)$ & $19(50.0)$ & 0.935 & $48(49.5)$ \\
\hline COPD, n (\%) & $10(17.0)$ & $5(13.2)$ & 0.614 & $15(15.5)$ \\
\hline CKD (stadium $\geq 3), \mathrm{n}(\%)$ & $16(27.6)$ & $12(31.6)$ & 0.674 & $28(28.9)$ \\
\hline \multicolumn{5}{|c|}{ MEDICATION USE BEFORE HOSPITALIZATION (available for 95) } \\
\hline ACE-I, n (\%) & $30(52.6)$ & $28(73.7)$ & 0.039 & $58(61.1)$ \\
\hline ARB, n (\%) & $5(8.8)$ & $5(13.2)$ & 0.495 & $10(10.5)$ \\
\hline B blocker, n (\%) & $41(71.9)$ & $33(86.8)$ & 0,086 & $74(77.9)$ \\
\hline Aldosterone antagonists, $\mathrm{n}(\%)$ & $22(38.6)$ & $9(23.7)$ & 0.129 & $31(32.6)$ \\
\hline Diuretics, n (\%) & $40(70.2)$ & $29(76.3)$ & 0.511 & $69(72.6)$ \\
\hline Iwabradine, n (\%) & $0(0.0)$ & $2(5.3)$ & 0.080 & $2(2.1)$ \\
\hline Digoxin, n (\%) & $3(5.3)$ & $3(7.9)$ & 0.605 & $6(6.3)$ \\
\hline Amiodarone, $\mathrm{n}(\%)$ & $10(17.5)$ & $3(7.9)$ & 0.180 & $13(13.7)$ \\
\hline
\end{tabular}

ACE-I — angiotensin-converting-enzyme inhibitors; ARB — angiotensin II receptor blockers; BMI — body mass índex; CKD — chronic kidney disease; COPD — chronic obstructive pulmonary disease; CRT — cardiac resynchronization therapy; DBP — diastolic blood pressure; HR — heart rate; ICD — implantable cardioverter defibrillator; MRA — mineralocorticoid receptor antagonista; NYHA — New York Heart Association; SBP — systolic blood pressure 
Table 2. The comparison between patients with LVEF $<40 \%$ and LVEF $\geq 40 \%$ - echocardiography

\begin{tabular}{|c|c|c|c|}
\hline & $\begin{array}{c}\text { LVEF }<40 \% \\
N=59\end{array}$ & $\begin{array}{c}\text { LVEF } \geq \mathbf{4 0 \%} \\
n=\mathbf{3 8}\end{array}$ & $\mathbf{p}$ \\
\hline \multicolumn{4}{|c|}{$\mathrm{n}(\%) /$ mean $\pm \mathrm{SD}$} \\
\hline LVEDD $[\mathrm{mm}]$, mean $\pm \mathrm{SD}$ & $65.0 \pm 8.4$ & $51.4 \pm 6.6$ & 0.000001 \\
\hline RVEDD $[\mathrm{mm}]$, mean $\pm \mathrm{SD}$ & $36.4 \pm 6.2$ & $33.7 \pm 4.6$ & 0.081 \\
\hline $\mathrm{LA}[\mathrm{mm}]$, mean $\pm \mathrm{SD}$ & $48.7 \pm 5.2$ & $45.6 \pm 6.7$ & 0.015 \\
\hline LVEF [\%], mean \pm SD & $27.7 \pm 6.5$ & $52.2 \pm 8.3$ & 0.000001 \\
\hline $\mathrm{MR}^{85}, \mathrm{n}(\%)$ & $32(65.3)$ & $14(38.9)$ & 0.016 \\
\hline $\mathrm{AS}^{85}, \mathrm{n}(\%)$ & $2(4.1)$ & 7 (19.4) & 0.023 \\
\hline $\mathrm{AR}^{85}, \mathrm{n}(\%)$ & $0(0.0)$ & $2(5.6)$ & 0.095 \\
\hline $\mathrm{TR}^{85}, \mathrm{n}(\%)$ & $19(38.8)$ & $15(41.7)$ & 0.707 \\
\hline
\end{tabular}

Upper index — number of subjects with sufficient valve assessment; AR — aortic regurgitation; AS — aortic stenosis; LA — left atrium; LVEDD - left ventricle end-diastolic dimension; RVEDD - right ventricle end-diastolic dimension; LVEF — left ventricle ejection fraction; MR - mitral regurgitation; TR - tricuspid regurgitation

Table 3. The comparison between patients with LVEF $<40 \%$ and LVEF $\geq 40 \%$ - laboratory data on admission

\begin{tabular}{|c|c|c|c|c|}
\hline & $\begin{array}{c}\text { LVEF }<40 \% \\
N=59\end{array}$ & $\begin{array}{c}\text { LVEF } \geq \mathbf{4 0} \% \\
\mathbf{N}=\mathbf{3 8}\end{array}$ & $\mathbf{p}$ & $\begin{array}{c}\text { Whole group } \\
\mathrm{N}=97\end{array}$ \\
\hline \multicolumn{5}{|c|}{ mean \pm SD } \\
\hline Creatinine $[\mathrm{mg} / \mathrm{dl}]$, mean $\pm \mathrm{SD}$ & $1.36 \pm 0.49$ & $1.24 \pm 0.55$ & 0.148 & $1.31 \pm 0.51$ \\
\hline eGFR MDRD $\left[\mathrm{ml} / \mathrm{min} / 1.73 \mathrm{~m}^{2}\right]$, mean $\pm \mathrm{SD}$ & $61.5 \pm 24.2$ & $63.2 \pm 23.0$ & 0.644 & $62.2 \pm 23.6$ \\
\hline Urea [mg/dl], mean \pm SD & $55.8 \pm 29.4$ & $51.6 \pm 21.6$ & 0.615 & $54.2 \pm 26.6$ \\
\hline NT-proBNP $[\mathrm{pg} / \mathrm{ml}]$, mean \pm SD & $7991 \pm 8463$ & $3453 \pm 3031$ & 0.0008 & $6213 \pm 7195$ \\
\hline hsTnT [ng/l], mean \pm SD & $124.5 \pm 292.2$ & $79.2 \pm 212.2$ & 0.219 & $106.9 \pm 263.4$ \\
\hline $\mathrm{Hb}[\mathrm{g} / \mathrm{dl}]$, mean $\pm \mathrm{SD}$ & $13.1 \pm 2.0$ & $11.8 \pm 2.4$ & 0.003 & $12.6 \pm 2.3$ \\
\hline Hematocrit [\%], mean \pm SD & $39.8 \pm 5.7$ & $36.4 \pm 6.6$ & 0,003 & $38.5 \pm 6.2$ \\
\hline
\end{tabular}

eGFR - estimated glomerular filtration rate; Hgb - hemoglobina; hsTnT — high-sensitive cardiac troponin T; NTproBNP — N-terminal fragment of the prohormone brain-type natriuretic peptide

LVEF seemed to have less pronounced abnormalities in their hemodynamic profile, with higher values of parameters indicating cardiac function as a pump and lower TFC. However, it is worth noting that the symptoms reported by patients with HFmrEF/HFpEF were not any less pronounced than those reported by patients with LVEF < 40\%.

Although, the whole study group was predominantly male, the proportion of men was noticeably lower in the HFmrEF/HFpEF subgroup. Data from AHF registries show the proportion of women in this subgroup to range from $53 \%$ to $72.4 \%$ [21-24].

The patients from the HFmrEF/HFpEF subgroup were older and had higher rates of concomitant chronic conditions and lower rates of post-infarct HF etiology [21]. Patients with HFrEF are known to have higher rates of coronary artery disease, while those with HFpEF have higher rates of atrial fibrillation, hypertension, and anaemia $[6,17,18,25]$. Particularly interesting were our findings on anaemia, which are consistent with earlier reports on higher rates of this condition in HFpEF [26, 27]. Our findings regarding the rates of chronic kidney disease (CKD) being comparable in both subgroups were also consistent to those reported in many registries [23, 28-31]. However, Bishu et al. [27], who assessed renal function based on cystatin $\mathrm{C}$ levels, demonstrated higher rates of CKD in patients with HFmrEF/HFpEF, which was most likely due to the selected diagnostic marker, as cystatin $C$ is highly sensitive [32, 33-36]. Quiroz et al. made similar observations, finding higher admission creatinine levels in patients with LVEF > 50\% [21].

In our study, the two subgroups differed the most in terms of the rates of hypertension, with as many as $50 \%$ of HFmrEF/HFpEF patients presenting with a blood pressure of over $140 / 90 \mathrm{mmHg}$. This is consistent with earlier reports $[6,27,37]$ and may be responsible for the higher rates of renin-angiotensin-aldosterone system (RAAS) inhibitors in the subgroup with LVEF $\geq 40 \%$, although some reports have indicated higher rates of calcium-channel blockers and alpha-blockers, rather 
Table 4. The comparison between patients with LVEF $<40 \%$ and LVEF $\geq 40 \%$ - impedance cardiography

\begin{tabular}{|c|c|c|c|c|c|}
\hline & $\begin{array}{c}\text { LVEF }<40 \% \\
N=59\end{array}$ & $\begin{array}{c}\text { LVEF } \geq \mathbf{4 0} \% \\
\mathbf{N}=\mathbf{3 8}\end{array}$ & $\mathbf{p}$ & \multicolumn{2}{|c|}{$\begin{array}{l}\text { LVEF } \\
\text { VS. }\end{array}$} \\
\hline & \multicolumn{2}{|c|}{$\mathrm{n}(\%) /$ mean \pm SD } & & $\mathbf{R}$ & $\mathbf{P}$ \\
\hline \multicolumn{6}{|l|}{ IMPEDANCE CARDIOGRAPHY } \\
\hline $\mathrm{HR}[\mathrm{bpm}]$, mean $\pm \mathrm{SD}$ & $83.8 \pm 22.8$ & $77.7 \pm 20.1$ & 0.188 & -0.03 & 0.784 \\
\hline $\mathrm{SBP}[\mathrm{mmHg}]$, mean $\pm \mathrm{SD}$ & $114.6 \pm 16.9$ & $136.1 \pm 29.5$ & 0.0002 & 0.38 & 0.0001 \\
\hline $\mathrm{DBP}[\mathrm{mmHg}]$, mean $\pm \mathrm{SD}$ & $73.7 \pm 11.5$ & $72.2 \pm 12.0$ & 0.418 & -0.04 & 0.718 \\
\hline $\mathrm{SI}\left[\mathrm{ml}^{*} \mathrm{~m}^{-2}\right]$, mean $\pm \mathrm{SD}$ & $36.0 \pm 10.4$ & $44.4 \pm 13.7$ & 0.004 & 0.30 & 0.005 \\
\hline $\mathrm{Cl}\left[\mathrm{ml}^{*} \mathrm{~m}^{-2 *} \mathrm{~min}^{-1}\right]$, mean $\pm \mathrm{SD}$ & $2.86 \pm 078$ & $3.12 \pm 0,80$ & 0.208 & 0.24 & 0.026 \\
\hline $\mathrm{HI}\left[\Omega \cdot \mathrm{s}^{-2}\right]$, mean $\pm \mathrm{SD}$ & $7.82 \pm 4.77$ & $12.0 \pm 6.75$ & 0,002 & 0,38 & 0.0003 \\
\hline $\mathrm{ACl}\left[1 * 100^{-1 *} \mathrm{~S}^{-2}\right]$, mean $\pm \mathrm{SD}$ & $59.6 \pm 23.3$ & $77.1 \pm 39.1$ & 0.051 & 0.25 & 0.022 \\
\hline VI $\left[1 * 1000^{-1 *} S^{-1}\right]$, mean $\pm S D$ & $38.2 \pm 15.7$ & $48.1 \pm 25.5$ & 0.120 & 0.22 & 0.047 \\
\hline SVRI $\left[\mathrm{dyn}^{*} \mathrm{~s}^{*} \mathrm{~cm}^{-5 *} \mathrm{~m}^{2}\right]$, mean $\pm \mathrm{SD}$ & $2424 \pm 733$ & $2292 \pm 802$ & 0.457 & -0.17 & 0.131 \\
\hline TFC $\left[1^{*} \mathrm{kOhm}^{-1}\right]$, mean $\pm \mathrm{SD}$ & $37.4 \pm 8.2$ & $33.7 \pm 6.5$ & 0.009 & -0.28 & 0.005 \\
\hline STR [\%], mean \pm SD & $0.54 \pm 0.33$ & $0.36 \pm 0,13$ & 0.001 & -0.38 & 0.0002 \\
\hline PEP $[\mathrm{ms}]$, mean $\pm \mathrm{SD}$ & $137.5 \pm 62.1$ & $103.2 \pm 34.0$ & 0.003 & -0.38 & 0.0002 \\
\hline LVET [ms], mean \pm SD & $272.5 \pm 47.7$ & $303.1 \pm 62.8$ & 0.018 & 0.18 & 0.100 \\
\hline $\mathrm{SI}<35$ ml/m2, n (\%) & $23(38.9)$ & $8(21.1)$ & 0.041 & - & - \\
\hline TFC > 35 kOhm, n (\%) & $34(57.6)$ & $12(31.6)$ & 0.012 & - & - \\
\hline
\end{tabular}

$\mathrm{ACl}$ - acceleration time índex; Cl — cardiac índex; DBP — diastolic blood pressure; HI — Heather índex; HR — heart rate; LVET — left ventricular ejection time; PEP — pre-ejection period; SBP — systolic blood pressure; STR - systolic time ratio; SVRI — systemic vascular resistance índex; TFC — thoracic fluid contente; SI — stroke índex; VI — velocity index

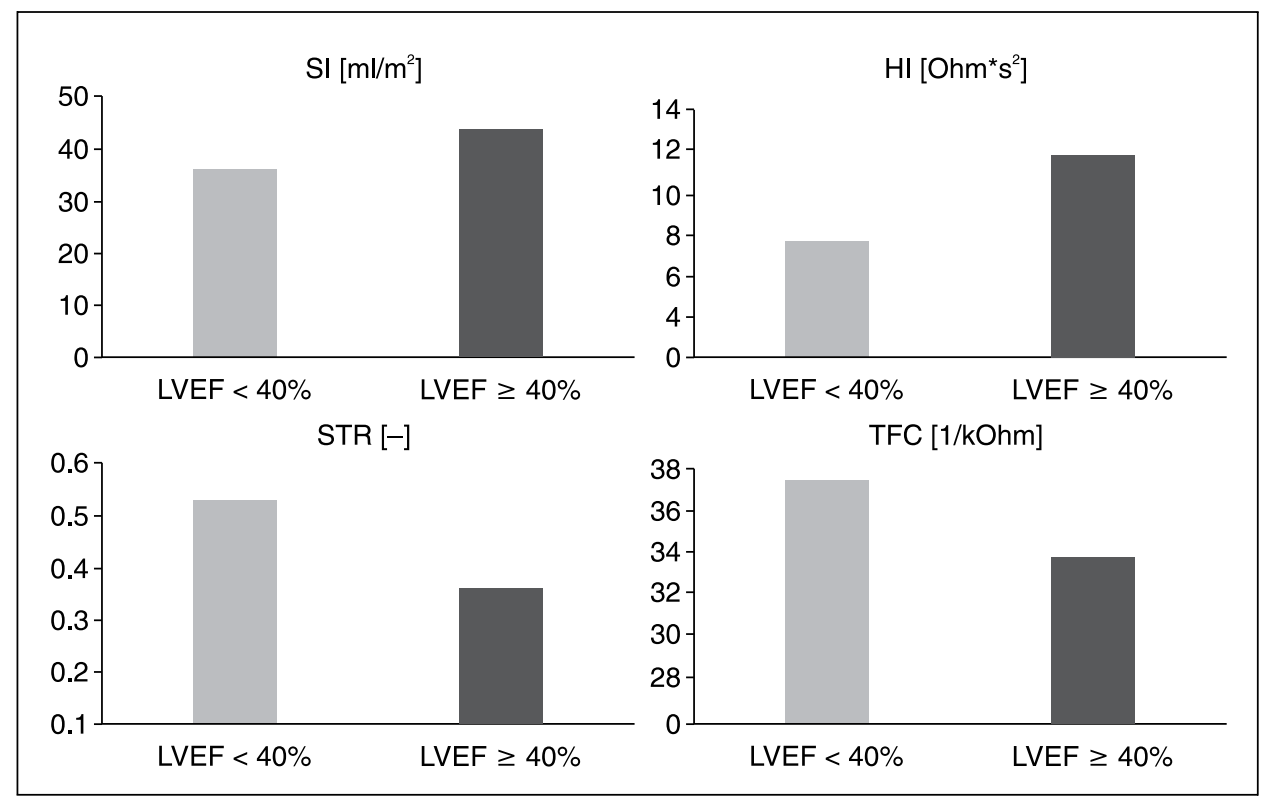

Figure 2. The comparison of hemodynamic parameters between patients with LVEF $<40 \%$ and LVEF $\geq 40 \%$

than RAAS inhibitors, in patients with $\operatorname{HFpEF}[24,27]$. The lower rates of RAAS inhibitor use in patients with HFrEF may have been due to the higher rates of objective clinical contraindications (e.g. hypotension, renal dysfunction, hyperkalemia) in this group.
Our findings demonstrated that, in comparison with patients with HFrEF, patients with HFmrEF/HFpEF had lower natriuretic peptide levels [38-40], which could indicate a lower myocardial load in the latter subgroup. However, the fact that the HFmrEF/HFpEF subgroup 
had higher rates of obesity may have also played a role, as low levels of natriuretic peptides may be due to increased natriuretic peptide absorption by adipocytes [41] as well as their reduced production as part of disrupted hormonal metabolism in the obese [42].

Impedance cardiography assessments revealed significant differences in hemodynamic profiles between the study subgroups stratified by LVEF. To our knowledge, this is the first report of this kind. Our findings demonstrated low LVEF to be reflected by lower ICG parameters of cardiac function as a pump $(\mathrm{SI}, \mathrm{Cl}, \mathrm{HI}$, $\mathrm{ACl}, \mathrm{VI}$ ). The values of these parameters in the HFrEF subgroup were comparable to those presented in earlier reports. Kaszuba et al. demonstrated a relationship between the ejection fraction and PEP, LVET, and STR, although that particular study included patients with no manifestations of HF exacerbation [43]. On the other hand, the hemodynamic profile of left ventricular function in the HFmrEF/HFpEF subgroup more closely resembled that in patients with uncomplicated hypertension. Studies evaluating hemodynamic parameters in hypertensive patients showed that even diastolic dysfunction alone was reflected in lower values of SI, $\mathrm{VI}, \mathrm{ACl}$, and $\mathrm{HI}$ as well as a higher SVRI [44, 45].

It seemed advisable to compare the subgroups also in terms of TFC, a parameter useful in differentiating the causes of dyspnea and assessing pulmonary congestion $[46,47]$. We found that, although the rates of patients with elevated TFC were considerable in both subgroups, they were noticeably higher in patients with HFrEF (57.6 vs. 31.6\%). Only one in three patients with HFmrEF exhibited marked pulmonary congestion. This indicates that diuretic treatment in this subgroup may not always be as effective as expected.

Our findings clearly showed differences between the hemodynamic profiles of patients with HFmrEF/HFpEF and of those with HFrEF. This suggests that the reported symptoms could be due mainly to other, concomitant conditions (poorly controlled hypertension, arrhythmia, or acute exacerbation of CKD, etc.). An ostensibly "better" hemodynamic profile does not exclude a poor clinical condition and severe symptoms. Moreover, the complexity of potential pathomechanisms makes it more difficult to select optimal treatment. Therefore, the diagnostic assessments in these patients should help select a treatment most suitable for the predominant cause of HF exacerbation.

Our findings may explain why it is so difficult to obtain robust scientific evidence for the effectiveness of selected medications in treating patients with HFmrEF/HFpEF. In such a non-homogeneous group [1, 48] the use of varied regimens, based on individual hemodynamic profiles may be a better management strategy. Therefore, ICG may be a practical tool in this group of patients, as its usefulness in selecting optimal treatments based on the individual hemodynamic disturbances has been already demonstrated in patients with hypertension $[49,50]$.

\section{Study limitations}

One indisputable limitation of our study is the small sample size. The observed differences in hemodynamic profiles may have been partly due to the uneven distribution of the sexes between the two subgroups. However, this fact should not be a significant confounding factor, as both subgroups were predominantly male. Another significant limitation was the 24-hour window allowed for hemodynamic assessment, as the hemodynamic profile may change even within less than an hour of initiating effective treatment. On the other hand, the varied time of echocardiographic examination was less problematic, as the LVEF value during clinical stabilization is considered to be the most reliable prognostic factor.

\section{Conclusion}

This study confirms earlier observations on the differences between patients with significantly impaired left ventricular systolic function versus those with mildly impaired and preserved left the ventricular systolic function. Despite the fact that left ventricular function does not determine the severity of clinical presentation in patients with decompensated HF, the observed differences in hemodynamic parameters demonstrated a non-homogeneity of the pathomechanisms and causes of decompensated HF. These findings prompt further studies on the use of ICG in patients hospitalized due to HF exacerbation.

\section{Disclosure of interest: The authors declared no conflict of interest}

\section{List of abbreviations}
ACEI - angiotensin-converting-enzyme inhibitors
$\mathrm{ACl}$ - acceleration index
AHF - acute heart failure
AR - aortic regurgitation
ARB - angiotensin II receptor blocker
AS - aortic stenosis
$\mathrm{BMI}$ - body mass index
$\mathrm{Cl}$ - cardiac index
CKD - chronic kidney disease
COPD - chronic obstructive pulmonary disease 
CRT - cardiac resynchronization therapy

CVP - central venous pressure

DBP — diastolic blood pressure

EF - ejection fraction

eGFR - estimated glomerular filtration rate

ESC - European Society of Cardiology

$\mathrm{Hgb}$ - hemoglobin

$\mathrm{HF}$ - heart failure

HFmrEF — heart failure with mid-range ejection fraction

HFpEF - heart failure with preserved ejection fraction

HFrEF - heart failure with reduced ejection fraction

$\mathrm{HI}$ - Heather index

$\mathrm{HR}$ - heart rate

hsTnT — high-sensitivity troponin T

ICD — implantable cardioverter defibrillator

ICG — impedance cardiography

IVS - interventricular septum

LA - left atrium

LVEDD - left ventricular end-diastolic diameter

LVEF — left ventricular ejection fraction

MDRD - modification of diet in renal disease

MRA - mineralocorticoid receptor antagonist

NTproBNP - N-terminal pro-brain natriuretic peptide

NYHA - New York Heart Association

PEP - pre-ejection period

RVEDD - right ventricular end-diastolic diameter

SBP — systolic blood pressure

$\mathrm{SD}$ - standard deviation

$\mathrm{SI}$ - stroke index

STR - systolic time ratio

SVRI - systemic vascular resistance index

TFC - thoracic fluid content

TRC - the time interval between the R-wave peak (in

ECG) and the C-point (in ICG)

$\mathrm{TR}$ - tricuspid regurgitation

$\mathrm{VI}$ - velocity index

\section{References}

1. Ponikowski P, Voors AA, Anker SD, et al. Authors/Task Force Members, Document Reviewers. 2016 ESC Guidelines for the diagnosis and treatment of acute and chronic heart failure: The Task Force for the diagnosis and treatment of acute and chronic heart failure of the European Society of Cardiology (ESC). Developed with the special contribution of the Heart Failure Association (HFA) of the ESC. Eur J Heart Fail. 2016; 18(8): 891-975, doi: 10.1002/ejhf.592, indexed in Pubmed: 27207191.

2. Abraham WT, Adams KF, Fonarow GC, et al. ADHERE Scientific Advisory Committee and Investigators, ADHERE Study Group. In-hospital mortality in patients with acute decompensated heart failure requiring intravenous vasoactive medications: an analysis from the Acute Decompensated Heart Failure National Registry (ADHERE). J Am Coll Cardiol. 2005; 46(1): 57-64, doi: 10.1016/j.jacc.2005.03.051, indexed in Pubmed: 15992636.

3. Moleerergpoom W, Hengrussamee K, Piyayotai D, et al. Predictors of in-hospital mortality in acute decompensated heart failure (Thai ADHERE). J Med Assoc Thai. 2013; 96(2): 157-164, indexed in Pubmed: 23936980.

4. Chan MMY, Lam CSP. How do patients with heart failure with preserved ejection fraction die? Eur J Heart Fail. 2013; 15(6): 604-613, doi: 10.1093/eurihf/hft062, indexed in Pubmed: 23610137.
5. Rich JD, Burns J, Freed BH, et al. Beta-Blockers in Heart Failure Collaborative Group, Meta-Analysis Global Group in Chronic Heart Failure (MAGGIC), Meta-Analysis Global Group in Chronic Heart Failure MAGGIC, Beta-Blockers in Heart Failure Collaborative Group, Meta-analysis Global Group in Chronic Heart Failure (MAGGIC), Meta-Analysis Global Group in Chronic Heart Failure, Meta-Analysis Global Group in Chronic Heart Failure, MAGGIC Investigators, Meta-analysis Global Group in Chronic Heart Failure (MAGGIC) Investigators, Meta-Analysis Global Group In Chronic Heart Failure (MAGGIC), Meta-analysis Global Group in Chronic Heart Failure (MAGGIC). The survival of patients with heart failure with preserved or reduced left ventricular ejection fraction: an individual patient data meta-analysis. Eur Heart J. 2012; 33(14): 1750-1757, doi: 10.1093/eurheartj/ehr254, indexed in Pubmed: 21821849.

6. Fonarow GC, Stough WG, Abraham WT, et al. OPTIMIZE-HF Investigators and Hospitals. Characteristics, treatments, and outcomes of patients with preserved systolic function hospitalized for heart failure: a report from the OPTIMIZE-HF Registry. J Am Coll Cardiol. 2007; 50(8): 768-777, doi: 10.1016/j.jacc.2007.04.064, indexed in Pubmed: 17707182

7. Maisel AS, Peacock WF, McMullin N, et al. Timing of immunoreactive B-type natriuretic peptide levels and treatment delay in acute decompensated heart failure: an ADHERE (Acute Decompensated Heart Failure National Registry) analysis. J Am Coll Cardiol. 2008; 52(7): 534-540, doi: 10.1016/j.jacc.2008.05.010, indexed in Pubmed: 18687247.

8. Hunter BR, Martindale J, Abdel-Hafez O, et al. Approach to Acute Heart Failure in the Emergency Department. Prog Cardiovasc Dis. 2017; 60(2): 178-186, doi: 10.1016/j.pcad.2017.08.008, indexed in Pubmed: 28865801

9. Peacock WF, Cannon CM, Singer AJ, et al. Considerations for initial therapy in the treatment of acute heart failure. Crit Care. 2015; 19: 399, doi: 10.1186/s13054-015-1114-3, indexed in Pubmed: 26556500.

10. Sanchez CE, Richards DR. Contemporary in-hospital management strategies for acute decompensated heart failure. Cardiol Rev. 2011; 19(3): 122-129, doi: 10.1097/CRD.0b013e318214022b, indexed in Pubmed: 21464640

11. Vernon C, Phillips CR. Pulmonary artery catheters in acute heart failure: end of an era? Crit Care. 2009; 13(6): 1003, doi: 10.1186/cc8113, indexed in Pubmed: 19930618.

12. Maurer MS. Heart failure with a normal ejection fraction (HFNEF): embracing complexity. J Card Fail. 2009; 15(7): 561-564, doi: 10.1016/j. cardfail.2009.04.004, indexed in Pubmed: 19700131.

13. Aurigemma GP, Gaasch WH. Clinical practice. Diastolic heart failure. N Engl J Med. 2004; 351(11): 1097-1105, doi: 10.1056/NEJMcp022709, indexed in Pubmed: 15356307.

14. Burkhoff D, Maurer MS, Packer M. Heart failure with a normal ejection fraction: is it really a disorder of diastolic function? Circulation. 2003; 107(5): 656-658, indexed in Pubmed: 12578861

15. Bursi F, Weston SA, Redfield MM, et al. Systolic and diastolic heart failure in the community. JAMA. 2006; 296(18): 2209-2216, doi: 10.1001/jama.296.18.2209, indexed in Pubmed: 17090767

16. Steinberg BA, Zhao X, Heidenreich PA, et al. Get With the Guidelines Scientific Advisory Committee and Investigators. Trends in patients hospitalized with heart failure and preserved left ventricular ejection fraction: prevalence, therapies, and outcomes. Circulation. 2012; 126(1): 65-75, doi: 10.1161/CIRCULATIONAHA.111.080770, indexed in Pubmed: 22615345

17. Owan TE, Hodge DO, Herges RM, et al. Trends in prevalence and outcome of heart failure with preserved ejection fraction. $\mathrm{N}$ Engl J Med. 2006; 355(3): 251-259, doi: 10.1056/NEJMoa052256, indexed in Pubmed: 16855265

18. Bhatia RS, Tu JV, Lee DS, et al. Outcome of heart failure with preserved ejection fraction in a population-based study. N Engl J Med. 2006; 355(3): 260-269, doi: 10.1056/NEJMoa051530, indexed in Pubmed: 16855266.

19. Krzesiński P, Gielerak G, Kowal J. [Impedance cardiography - a modern tool for monitoring therapy of cardiovascular diseases]. Kardiol Pol. 2009; 67(1): 65-71, indexed in Pubmed: 19253194.

20. Smilde TDJ, van Veldhuisen DJ, Navis G, et al. Drawbacks and prognostic value of formulas estimating renal function in patients with chronic heart failure and systolic dysfunction. Circulation. 2006; 114(15): 1572-1580, doi: 10.1161/CIRCULATIONAHA.105.610642, indexed in Pubmed: 17015793

21. Quiroz R, Doros G, Shaw P, et al. Comparison of characteristics and outcomes of patients with heart failure preserved ejection fraction versus reduced left ventricular ejection fraction in an urban cohort. Am J Cardiol. 2014; 113(4): 691-696, doi: 10.1016/j.amjcard.2013.11.014, indexed in Pubmed: 24484862 
22. Hsich EM, Grau-Sepulveda MV, Hernandez AF, et al. Sex differences in in-hospital mortality in acute decompensated heart failure with reduced and preserved ejection fraction. Am Heart J. 2012; 163(3): 430-7, 437 e1, doi: 10.1016/j.ahj.2011.12.013, indexed in Pubmed: 22424014.

23. Villacorta H, Saenz-Tello BF, Santos EB, et al. Renal dysfunction and anemia in patients with heart failure with reduced versus normal ejection fraction. Arq Bras Cardiol. 2010; 94(3): 357-63, 378, indexed in Pubmed: 20730266.

24. de Denus S, Lavoie J, Ducharme A, et al. Differences in biomarkers in patients with heart failure with a reduced vs a preserved left ventricular ejection fraction. Can J Cardiol. 2012; 28(1): 62-68, doi: 10.1016/j. cjca.2011.09.007, indexed in Pubmed: 22104539.

25. Cheng RK, Cox M, Neely ML, et al. Outcomes in patients with heart failure with preserved, borderline, and reduced ejection fraction in the Medicare population. Am Heart J. 2014; 168(5): 721-730, doi: 10.1016/j.ahj.2014.07.008, indexed in Pubmed: 25440801

26. Mentz RJ, Kelly JP, von Lueder TG, et al. Noncardiac comorbidities in heart failure with reduced versus preserved ejection fraction. J Am Coll Cardiol. 2014; 64(21): 2281-2293, doi: 10.1016/j.jacc.2014.08.036, indexed in Pubmed: 25456761.

27. Bishu K, Deswal A, Chen $\mathrm{HH}$, et al. Biomarkers in acutely decompensated heart failure with preserved or reduced ejection fraction. Am Heart J. 2012; 164(5): 763-770.e3, doi: 10.1016/j.ahj.2012.08.014, indexed in Pubmed: 23137508.

28. Guisado-Espartero ME, Salamanca-Bautista P, Aramburu-Bodas Ó, et al. RICA investigators group. Heart failure with mid-range ejection fraction in patients admitted to internal medicine departments: Findings from the RICA Registry. Int J Cardiol. 2018; 255: 124-128, doi: 10.1016/j.ijcard.2017.07.101, indexed in Pubmed: 29305104

29. Steinberg BA, Zhao X, Heidenreich PA, et al. Get With the Guidelines Scientific Advisory Committee and Investigators. Trends in patients hospitalized with heart failure and preserved left ventricular ejection fraction: prevalence, therapies, and outcomes. Circulation. 2012 126(1): 65-75, doi: 10.1161/CIRCULATIONAHA.111.080770, indexed in Pubmed: 22615345.

30. Brouwers FP, de Boer RA, van der Harst P, et al. Incidence and epidemiology of new onset heart failure with preserved vs. reduced ejection fraction in a community-based cohort: 11-year follow-up of PREVEND. Eur Heart J. 2013; 34(19): 1424-1431, doi: 10.1093/eurheartj/eht066, indexed in Pubmed: 23470495.

31. van Deursen VM, Urso R, Laroche C, et al. Co-morbidities in patients with heart failure: an analysis of the European Heart Failure Pilot Survey. Eur J Heart Fail. 2014; 16(1): 103-111, doi: 10.1002/ejhf.30, indexed in Pubmed: 24453099

32. Arimoto T, Takeishi Y, Niizeki T, et al. Cystatin C, a novel measure of renal function, is an independent predictor of cardiac events in patients with heart failure. J Card Fail. 2005; 11(8): 595-601, doi: 10.1016/j. cardfail.2005.06.001, indexed in Pubmed: 16230262.

33. Carrasco-Sánchez FJ, Galisteo-Almeda L, Páez-Rubio I, et al. Prognostic value of cystatin $\mathrm{C}$ on admission in heart failure with preserved ejection fraction. J Card Fail. 2011; 17(1): 31-38, doi: 10.1016/j. cardfail.2010.07.248, indexed in Pubmed: 21187262.

34. Dharnidharka VR, Kwon C, Stevens G. Serum cystatin C is superior to serum creatinine as a marker of kidney function: a meta-analysis. Am J Kidney Dis. 2002; 40(2): 221-226, doi: 10.1053/ajkd.2002.34487, indexed in Pubmed: 12148093.

35. Finney $\mathrm{H}$, Newman DJ, Price CP. Adult reference ranges for serum cystatin $\mathrm{C}$, creatinine and predicted creatinine clearance. Ann Clin Biochem. 2000; 37 ( Pt 1): 49-59, doi: 10.1258/0004563001901524, indexed in Pubmed: 10672373.

36. Laterza OF, Price CP, Scott MG. Cystatin C: an improved estimator of glomerular filtration rate? Clin Chem. 2002; 48(5): 699-707, indexed in Pubmed: 11978596.
37. Sweitzer NK, Lopatin M, Yancy CW, et al. Comparison of clinical features and outcomes of patients hospitalized with heart failure and normal ejection fraction ( $>$ or $=55 \%$ ) versus those with mildly reduced $(40 \%$ to $55 \%$ ) and moderately to severely reduced (<40\%) fractions. Am J Cardiol. 2008; 101(8): 1151-1156, doi: 10.1016/j.amjcard.2007.12.014, indexed in Pubmed: 18394450.

38. Benedict $\mathrm{CR}$, Weiner $\mathrm{DH}$, Johnstone $\mathrm{DE}$, et al. Comparative neurohormonal responses in patients with preserved and impaired left ventricular ejection fraction: results of the Studies of Left Ventricular Dysfunction (SOLVD) Registry. The SOLVD Investigators. J Am Coll Cardiol. 1993: 22(4 Suppl A): 146A-153A, indexed in Pubmed: 8376686

39. Kitzman DW, Little WC, Brubaker PH, et al. Pathophysiological characterization of isolated diastolic heart failure in comparison to systolic heart failure. JAMA. 2002; 288(17): 2144-2150, indexed in Pubmed: 12413374.

40. Maisel A, Hollander JE, Guss D, et al. Rapid Emergency Department Heart Failure Outpatient Trial investigators. Primary results of the Rapid Emergency Department Heart Failure Outpatient Trial (REDHOT). A multicenter study of B-type natriuretic peptide levels, emergency department decision making, and outcomes in patients presenting with shortness of breath. J Am Coll Cardiol. 2004; 44(6): 1328-1333, doi: 10.1016/j.jacc.2004.06.015, indexed in Pubmed: 15364340

41. Wang TJ, Larson MG, Levy D, et al. Impact of age and sex on plasma natriuretic peptide levels in healthy adults. Am J Cardiol. 2002; 90(3): 254-258, indexed in Pubmed: 12127613.

42. Lam CSP, Cheng S, Choong K, et al. Influence of sex and hormone status on circulating natriuretic peptides. J Am Coll Cardiol. 2011; 58(6): 618-626, doi: 10.1016/j.jacc.2011.03.042, indexed in Pubmed: 21798425

43. Kaszuba E, Scheel S, Odeberg H, et al. Comparing impedance cardiography and echocardiography in the assessment of reduced left ventricular systolic function. BMC Res Notes. 2013; 6: 114, doi: 10.1186/1756-0500-6-114, indexed in Pubmed: 23531417.

44. Krzesiński P, Gielerak $G$, Stańczyk $A$, et al. What does impedance cardiography add more to the assessment of left ventricular diastolic function in essential hypertension? Pol Merkur Lekarski. 2015; 39(234): 352-358, indexed in Pubmed: 26802686.

45. Krzesiński P, Gielerak G, Kowal J, et al. Usefulness of impedance cardiography in optimisation of antihypertensive treatment in patients with metabolic syndrome: a randomised prospective clinical trial. Kardiol Pol. 2012; 70(6): 599-607, indexed in Pubmed: 22718380.

46. Facchini $C$, Malfatto $G$, Giglio A, et al. Lung ultrasound and transthoracic impedance for noninvasive evaluation of pulmonary congestion in heart failure. J Cardiovasc Med (Hagerstown). 2016; 17(7): 510-517, doi: 10.2459/JCM.0000000000000226, indexed in Pubmed: 25575275.

47. Di Somma S, Lalle I, Magrini L, et al. Additive diagnostic and prognostic value of bioelectrical impedance vector analysis (BIVA) to brain natriuretic peptide, grey-zone' in patients with acute heart failure in the emergency department. Eur Heart J Acute Cardiovasc Care. 2014; 3(2): 167-175, doi: 10.1177/2048872614521756, indexed in Pubmed: 24477201

48. Sandesara PB, O'Neal WT, Kelli HM, et al. The Prognostic Significance of Diabetes and Microvascular Complications in Patients With Heart Failure With Preserved Ejection Fraction. Diabetes Care. 2018; 41(1): 150-155, doi: 10.2337/dc17-0755, indexed in Pubmed: 29051160

49. Taler SJ. Individualizing antihypertensive combination therapies: clinical and hemodynamic considerations. Curr Hypertens Rep. 2014; 16(7): 451, doi: 10.1007/s11906-014-0451-y, indexed in Pubmed: 24806735.

50. Krzesiński P, Gielerak GG, Kowal JJ. A patient-tailored" treatment of hypertension with use of impedance cardiography: a randomized, prospective and controlled trial. Med Sci Monit. 2013; 19: 242-250, doi: 10.12659/MSM.883870, indexed in Pubmed: 23558598. 